\title{
Electrochemical Impedance and Current Fluctuations Analysis During Slow Strain Rate Test of a UNS S30400 Stainless Steel in Low pH Media
}

\author{
Ivan N. Bastos ${ }^{*, a}$, Ricardo P. Nogueira ${ }^{b}$ and José A. C. Ponciano ${ }^{c}$ \\ ${ }^{a}$ Instituto Politécnico, Universidade do Estado do Rio de Janeiro, CP 97282, 28601-970 Nova Friburgo - RJ, Brazil \\ ${ }^{b}$ UPR15-CNRS “Interfaces et Systèmes Electrochimiques”, Université Pierre et Marie Curie, 4 Place Jussieu, \\ 75252 Paris Cedex 05, France \\ ${ }^{c}$ Laboratório de Corrosão - PEMM/COPPE, Universidade Federal do Rio de Janeiro CP 68505 , \\ 21945-970 Rio de Janeiro - RJ, Brazil
}

\begin{abstract}
Neste trabalho foi investigado o comportamento do aço inoxidável austenítico UNS S30400 em corrosão sob tensão em meios ácidos contendo cloreto à temperatura ambiente. Ensaios de impedância eletroquímica e ruído eletroquímico em corrente foram realizados a diversos níveis de carregamento concomitantemente com o tracionamento a baixa taxa de deformação em $\mathrm{pH} 0,00$ e 1,00 para avaliar a evolução das variáveis eletroquímicas relacionadas com a interface sob deformação. A partir dos resultados obtidos pôde-se constatar que, ao contrário do que ocorre em $\mathrm{pH}$ 1,00, o ataque corrosivo a pH 0,00 se caracteriza por intenso trincamento concomitante à instalação progressiva de um processo de corrosão generalizada da superfície metálica. O emprego conjunto das técnicas de impedância e ruído eletroquímico em corrente fornece informações complementares sobre a interdependência da dissolução e do trincamento do aço inoxidável à diferente agressividade representada pelo eletrólito.
\end{abstract}

This paper is aimed at investigating the electrochemical behavior of austenitic stainless steel UNS S30400 under stress corrosion cracking conditions in acidic solutions at room temperature. Electrochemical impedance spectroscopy and electrochemical current noise measurements were performed at different stress levels during slow strain rate tests at $\mathrm{pH} 0.00$ and 1.00 in order to evaluate the influence of mechanical deformation on the evolution of the electrochemical responses of the interface. Results have shown that, differently to what happens at $\mathrm{pH} 1.00$, the corrosive attack at $\mathrm{pH} 0.00$ is characterized by intensive cracking concomitantly to the progressive spreading out of uniform corrosion on the metallic surface. The coupling of both electrochemical impedance and current noise techniques provided complementary information about the interplay between dissolution and cracking of the stainless steel exposed to electrolytes of different aggressiveness.

Keywords: stress corrosion cracking, stainless steel, impedance spectroscopy, electrochemical noise

\section{Introduction}

The susceptibility to stress corrosion cracking, SCC, is one of the main drawbacks of austenitic stainless steels mainly in chloride-rich environments. Specifically, there are two main situations where chloride limits the use of austenitic stainless steel: neutral $\mathrm{pH}$ at high temperature and room temperature with low $\mathrm{pH} .^{1,2}$

Although being a widely studied phenomenon, the stress corrosion cracking dependence on $\mathrm{pH}$, as well as the

* e-mail: inbastos@iprj.uerj.br chloride threshold necessary to trigger the process, are not completely determined. Some papers have attempted to correlate the type of localized corrosion with $\mathrm{pH}$ and $\mathrm{Cl}^{-}$ content, ${ }^{3,4}$ even delimiting the immunity region for stress corrosion cracking, ${ }^{4}$ but these attempts were not sufficient to definitevely clarify this phenomenon. As an example, both the UNS S30100 and the UNS S31000 stainless steels, in spite of the fact that their austenite phase are respectively unstable and stable, have very close empirical correlations (expressed by equations like $\mathrm{pH}>\mathrm{A} \times \log \left(\mathrm{Cl}^{-}\right)+\mathrm{B}$ ) to describe the regions of $\mathrm{pH}$ where the SCC does not take place. As a matter of fact, empirical relations like the 
previous one are not able to encompass the complexity of SCC processes.

Carranza and Galvele ${ }^{5}$ strained wires of austenitic stainless steel at high strain rate $\left(\sim 10 \mathrm{~s}^{-1}\right)$ to find the range of electrode potentials where the kinetics of repassivation would be effectively related to SCC as suggested by Staehle. ${ }^{6}$ Bastos et al. ${ }^{7}$ employed this high strain rate to investigate the correlation between the electrolyte temperature and the susceptibility to SCC in rich-chloride environments. However, some problems arise when fast current transient occurs, as pointed out by Oltra et al. ${ }^{8}$ Besides the fact that SCC does not effectively take place in such high strain rates, they have illustrated the difficulties in gathering reliable information about these surface processes. The intrinsic uncertainty of measuring these transients, mainly after a single depassivation event, is due to the coupling of surface capacitances that provides, at first, the current necessary to repassivation. After this, the regulating device provides the same electrical charge to recover steady state conditions. In this situation the time constant of the measured transient does not correspond to the actual time constant but reflects the effects of unaffected area and the capabilities of current supply of the regulation device. Thus, according to Oltra et al. ${ }^{8}$ these results indicated that conventional devices are not well adequate to study repassivation kinetics and its correlation with SCC.

It is well known that the stress corrosion cracking is related to the corrosion of a localized region on the metallic surface whilst the rest of surface remains almost passivated. In this sense, SCC is generally accepted as being governed by the formation-rupture of a surface film on the metallic surface. Nevertheless, the literature is abundant in works where the stress corrosion cracking of austenitic stainless steel in room temperature occurs concomitantly with uniform corrosion, mainly at low $\mathrm{pH}$ values, ${ }^{3,9-12}$ even if this system is considered as being an exception to the one described above. ${ }^{9}{ }^{10}$ These results have been recently confirmed by Nishimura and Maeda ${ }^{13}$ who proposed an active path dissolution on SCC of austenitic stainless steels in acidic chloride solutions. Therefore, it is presumed that the electric current flowing between the different regions of the metallic surface must contain information about the type of corrosive process taking place on the electrode. This is why the use of a zero resistance ammeter (ZRA) to detect the current flowing between different areas of the metallic surface seems to be an appropriate technique to detect this process. In this sense, some authors have attempt to identify the elementary transients related to SCC susceptibility by using a ZRA. ${ }^{14,15}$ Results obtained by Gomez-Duran and Macdonald ${ }^{15}$ are of particular interest since they have demonstrated that significant coupling currents flowed from the cracks and could be effectively picked up by the ZRA apparatus. It is worth noticing, however, that one should not neglect the fact that the overall electrochemical behavior of the surface has also a key role in such a complex phenomenon as SCC. The present work is therefore devoted to the coupling of a macroscopic average approach by means of electrochemical impedance measurements to the stochastic approach, which is based on the use of a ZRA to measure the electrochemical current noise. Both techniques, electrochemical noise-ECN and electrochemical impedance spectroscopy-EIS, were employed to investigate some aspects of the SCC of austenitic stainless steel at low $\mathrm{pH}$ at room temperature in the presence of chloride, mainly focusing on the identification of the type of corrosive attack.

\section{Experimental}

The electrodes were prepared from commercial stainless steel UNS S30400 pretreated at $1323 \mathrm{~K}$ for 1 hour in argon atmosphere and subsequently quenched at room temperature water in order to obtain an austenitic microstructure free from carbide precipitation since the latter is known to affect the intergranular corrosion resistance. The samples used in slow strain rate test, SSRT, were machined in short transverse section of rolling. The surfaces were mechanically polished up to 600 grit with emery papers and stored in desiccator up to the moment of testing. The chemical composition of the alloy used is shown in Table 1.

Table 1. Chemical composition (\% wt.) of the UNS S30400 alloy matrix from which samples used in the experiments have been machined

\begin{tabular}{llllllll}
\hline $\mathrm{C}$ & $\mathrm{Cr}$ & $\mathrm{Ni}$ & $\mathrm{Mo}$ & $\mathrm{Si}$ & $\mathrm{S}$ & $\mathrm{Mn}$ & $\mathrm{Fe}$ \\
\hline 0.06 & 18.95 & 8.03 & 0.03 & 0.47 & 0.005 & 1.40 & balance \\
\hline
\end{tabular}

The electrolytes were prepared from an aqueous solution of $1 \mathrm{~mol} \mathrm{~L}^{-1} \mathrm{NaCl}$ to which different amounts of 1 mol $\mathrm{L}^{-1} \mathrm{HCl}$ were added to adjust the $\mathrm{pH}$ values to 0.00 and 1.00 under natural aeration. The working electrodes, $\mathrm{WE}$, were round samples of $4 \mathrm{~mm}$ in diameter and $16 \mathrm{~mm}$ in length tested at strain rate of $3 \times 10^{-6} \mathrm{~s}^{-1}$.

A $40 \mathrm{~mm}$ in diameter and $30 \mathrm{~mm}$ in length hollow cylinder of the same steel submitted to the same surface preparation was employed as a counter-electrode, CE, in the ECN measurements. The round WE and the CE were concentrically assembled inside the electrochemical.

The stressed WE and the non-stressed CE were 
connected by a ZRA as depicted in Figure 1. The analogue output current signals were digitized by a dynamic signal analyzer HP 3562A with proper anti-aliasing low-pass filtering, ${ }^{16}$ after direct current (DC) value elimination and amplification. The power spectrum densities (PSDs) of the digitized signals were calculated after Hann windowing to avoid artefacts related to the Fast-Fourier-Transform algorithm that assumes an intrinsic periodicity of the measured signal. ${ }^{17}$ The PSDs were averaged 10 times for increasing the measurement accuracy.

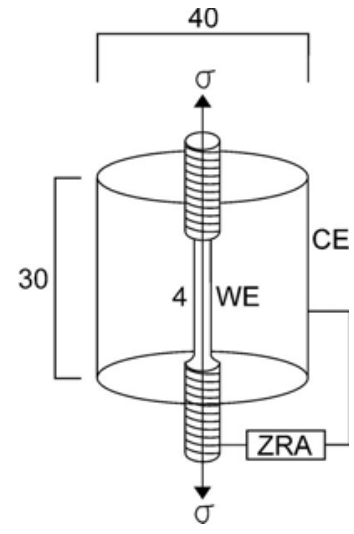

Figure 1. Schematic representation of the electrochemical cell employed for electrochemical noise measurements.

Polarization curves and EIS measurements were carried out in a conventional three-electrode electrochemical cell, with a platinum wire as $\mathrm{CE}$ and a satured calomel electrode as the reference electrode. The EIS measurements were performed at the corrosion potential during the straining of the samples under SSRT. A Solartron SI 1280 device delivered a perturbation signal of $8 \mathrm{mVpp}$ in the frequency range from $1 \mathrm{mHz}$ to $10 \mathrm{KHz}$ and calculated the $\mathrm{Z}(\mathrm{f})$ transfer function. The values of the electrochemical impedance modulus $|\mathrm{Z}(\mathrm{f})|$, were depicted in $\mathrm{Ohm}$ instead of $\mathrm{Ohmcm}^{2}$ due to the uncertainty of actual area of samples undergoing concomitant elongation and cracking.

\section{Results and Discussion}

The stress-strain SSRT curves at a strain rate of $3 \times 10^{-6} \mathrm{~S}^{-1}$ in air, as well as for samples immersed in $\mathrm{pH} 0.00$ and $\mathrm{pH}$ 1.00 solutions are shown in Figure 2. The air is assumed to be an inert environment and the corresponding stress $v s$. strain curve was used in a comparative basis to evaluate how aggressive is the acid solution in each case. The corrosive environment obviously affects the mechanical properties of the steel when stress corrosion cracking takes place. As it was expected, in acidic solutions, the values obtained for maximum elongation and maximum stress were lower than the respective ones obtained in air. This mechanical behavior is a consequence of the stress corrosion cracking that reduces the strength of the specimen.

Figure 3 shows the polarization curves of the austenitic stainless steel on both electrolytes for the non strained samples $(0 \mathrm{MPa})$ and at $375 \mathrm{MPa}$ (constant load applied before the cell was filled with the electrolyte). These curves represent the mean stationary behaviour of the interface: they clearly show a marked difference of the interface behaviour depending on the $\mathrm{pH}$. At 0.00 value the interface shows no clear passivation with a monotonically increasing current density before a saturation value is reached for an overpotential of about $200 \mathrm{mVsce}$. At pH 1.00 a net decrease in the current density indicates the existence of an active-passive transition which passivating property is soon lost in the case of the stressed sample since the current density increases again for continuously increasing potential values. It is also interesting to notice that regardless the $\mathrm{pH}$ of the electrolyte the mechanical loading

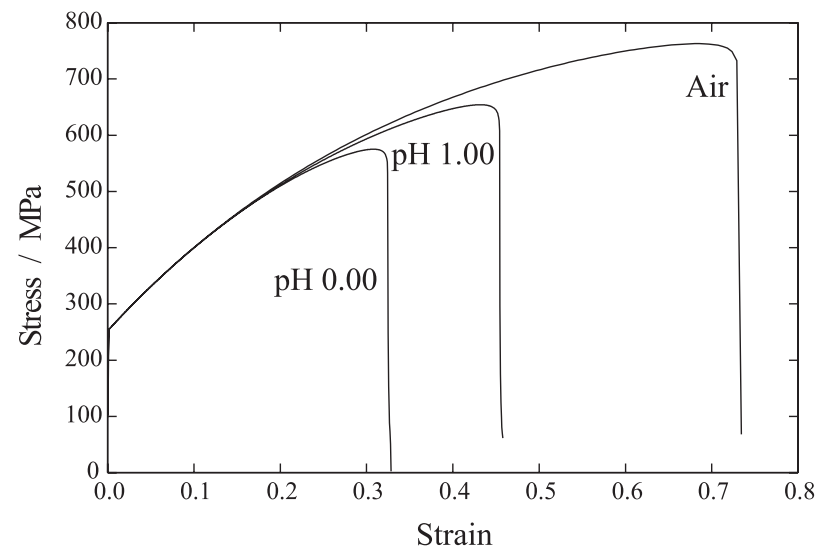

Figure 2. SSRT of UNS S30400 steel in $1 \mathrm{~mol} \mathrm{~L}^{-1} \mathrm{NaCl}+1 \mathrm{~mol} \mathrm{~L}^{-1}$ $\mathrm{HCl}$ solutions at $\mathrm{pH} 0.00$ and 1.00; strain rate of $3 \times 10^{-6} \mathrm{~s}^{-1}$ at room temperature.

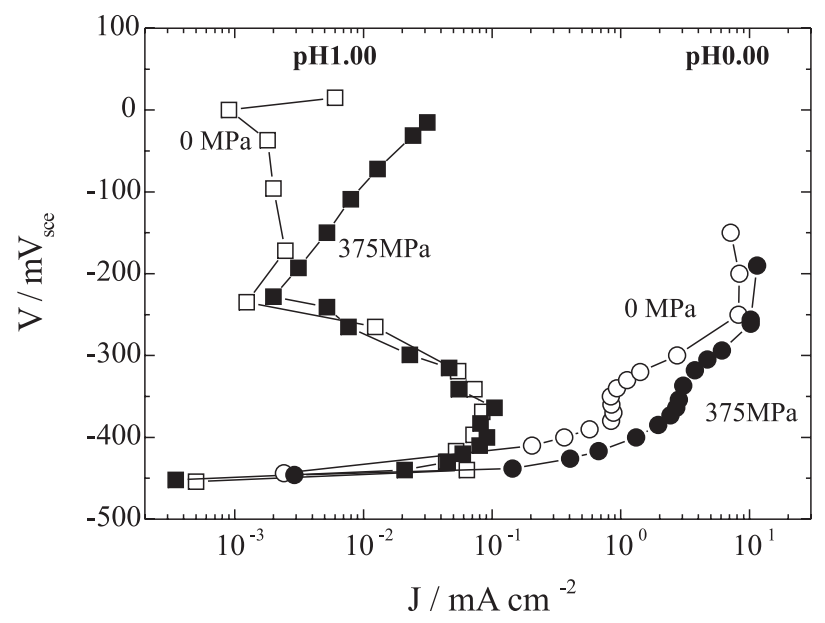

Figure 3. Polarization curves of UNS S30400 steel in $1 \mathrm{~mol} \mathrm{~L}^{-1} \mathrm{NaCl}$ $+1 \mathrm{~mol} \mathrm{~L}^{-1} \mathrm{HCl}$ solutions at $\mathrm{pH} 0.00$ and 1.00 in no-loaded and at constant load of $375 \mathrm{MPa}$ conditions. 
does not significantly change the stationary potential/ current relationship unless for the passive domain at $\mathrm{pH}$ 1.00 as pointed out above. This means that polarization curves are not prone to detect kinetic changes related to the interface evolution during the SSRT tests.

The overall behaviour of the polarization curves depicted in Figure 3 is consistent with data obtained from weight loss experiments carried out according to the ASTM G31-72 standard. ${ }^{18}$ In fact, after 200 hours of exposition the corrosion rates were found to be 1.75 and $0.23 \mathrm{~mm} \mathrm{y}^{-1}$ at $\mathrm{pH}$ 0.00 and 1.00 , respectively. One can then easily estimate the average diameter reduction during the first 40 hours of exposition ( $c a$. the elapsed time during the SSRT), which give $0.4 \%$ and $0.05 \%$ at $\mathrm{pH} 0.00$ and 1.00 , respectively. It then clearly appears that the dissolution process and the associated diameter reduction can not account for the significant changes in the mechanical properties depicted in Figure 2, which must then be ascribed to SCC phenomena.

Results presented up to now seem to confirm previous investigations from several authors which proposed the existence of an a priori unexpected coexistence of SCC phenomenon and uniform corrosion at low $\mathrm{pH}$ values, ${ }^{3,9-12}$ notwithstanding the fact that some articles point out the existence of a film on the metallic surface, even in these very aggressive acidic environments. ${ }^{5,9}$ This picture could explain both Figures 2 and 3 as well as the weight loss data. The $\mathrm{pH} 0.00$ solution appears then to promote intensive cracking concomitantly to uniform corrosion, whilst in $\mathrm{pH} 1.00$ uniform corrosion could be still present but in a lower extension and only a few cracks were observed in the surface. These preliminary results, however, should be further validated by more advanced electrochemical techniques as the EIS and ECN, which are done in the next paragraphs.

\section{Electrochemical impedance measurements}

The macroscopic electrochemical behavior of the system has been evaluated by electrochemical impedance measurements performed at open circuit conditions, i.e., at corrosion potential. Figure 4 shows the evolution of the impedance during the SSRT for $\mathrm{pH} 0.00$. The modulus gradually decreases as the mechanical load increases. One should notice, however, that this behavior is not to be ascribed only to the increment of the area that could effectively lower the impedance modulus. In fact, considering the WE as a rod of diameter $d_{0}$ and length $l_{0}$, the initial exposed surface is $\pi d_{0} l_{0}$. At least up to the point of maximum stress, the elongation is uniform and the WE volume can be assumed as being constant, i.e., $\Delta \mathrm{V}=0$ (beyond the maximum stress, the deformation is no longer

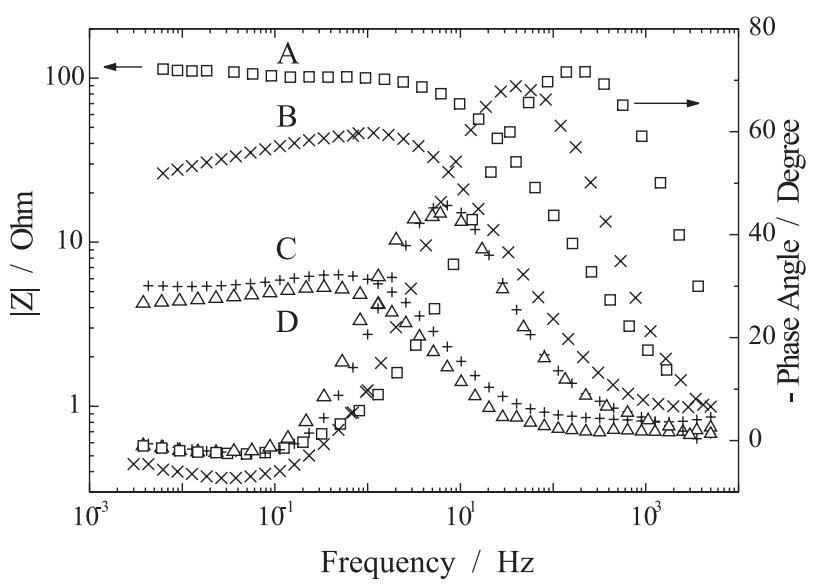

Figure 4. Electrochemical impedance of UNS S30400 steel in $1 \mathrm{~mol}$ $\mathrm{L}^{-1} \mathrm{NaCl}+1 \mathrm{~mol} \mathrm{~L}^{-1} \mathrm{HCl}$ solution at $\mathrm{pH} 0.00$ under SSRT at different stress levels: (A) $50 \mathrm{MPa}$, (B) $235 \mathrm{MPa}$, (C) $380 \mathrm{MPa}$, (D) $420 \mathrm{MPa}$.

homogeneous but confined to the necked region). Hence, taking a linear elongation of $40 \%$, for instance, the final diameter $d_{1}$ is given by $d_{1}=d_{0} / \sqrt{1.4}$, so that the ratio between the final and the initial exposed area is $\sqrt{1.4} \approx 18 \%$. It is then clear that the total increase of the electrode area, which occurs mainly at the final stages of the test, has a global effect on Z(f) far smaller than the two-decade modulus collapse shown in Figure 4. This strong compression of the diagrams is likely to be related mainly to the continuous rise of surface cracking: freshly exposed areas of side cracks have locally low impedance, and this is picked-up by the overall diagram in the form of parallel components that result in a global lower impedance which is effectively measured. Other features can also be related in a more or less important degree to this decrease of the electrochemical impedance modulus, such as the reduction of the thickness of the non-fractured film and the higher activation of the stressed but non-cracked areas. All these factors can cause the impedance modulus to decrease and indicate the global degradation of the material.

The Bode diagrams depicted in Figure 4 indicates the presence of a capacitive behavior at high frequency and an inductive one at low frequency. It then appears that the anodic dissolution, which is related to the low frequency inductive behavior, ${ }^{19}$ takes place simultaneously with cracking, as was already pointed out by Zhi et al. ${ }^{9}$ It is worth noticing that the surface activation that entails anodic dissolution is not only the result of cracks that exposed fresh bare metal, but is also related to phase transformations induced by the mechanical stress. ${ }^{20,21}$ Indeed, during the straining some volume fraction of austenite phase is continuously transformed into martensite $\alpha$ ', which is prone to show more severe corrosive attack than the austenite-base phase in chloride-rich environment. ${ }^{2,4,20}$ It is also interesting to note the shift of 
the characteristic frequency range into low frequency regions. This effect can not be attributed to the increase of area that occurs during the SSRT, as pointed out before, but rather to the change of nature of electrochemical processes, that means, the increasing contribution of larger time-constant electrochemical phenomena.

Bosch et al. ${ }^{22}$ have shown that SCC at SSRT yields a phase shift in EIS that is associated to the cracking conditions so that the electrochemical impedance can be useful in the monitoring of SCC phenomenon, specially in the frequency range $10-100 \mathrm{~Hz}$. Furthermore, the deeper were the drilled holes that acted as simulated crack length in that study, the more pronounced was the phase shift into low frequency regions. Results obtained at $\mathrm{pH} 0.00$ clearly confirm this fact. Moreover, Touzet et al. ${ }^{23}$ found that the evolution of impedance phase is closely linked to the stage of crack nucleation.

In $\mathrm{pH} 1.00$ solution the diagram presents a high frequency capacitive loop and an incomplete loop in the low frequency range that could indicate some mass transport limitation inside or across the film, as depicted in Figure 5. The values of impedance modulus are higher than the observed at $\mathrm{pH} 0.00$. The decrease in the impedance modulus during the SSRT (less than one decade) is clearly attenuated in comparison to the observed at $\mathrm{pH}$ 0.00 (more than two decades), which is consistent with the fact that the dissolution and cracking processes at $\mathrm{pH} 1.00$ does not occur so extensively as it was evidenced from the results presented in the previous section. As it was the case at $\mathrm{pH} 0.00$, the characteristic frequency at $\mathrm{pH} 1.00$ shifts towards low values, but in a less evident way, which is also coherent with the fact that at this $\mathrm{pH}$ the interface does not deteriorate so intensively. Indeed, the number of cracks found after the SSRT is 2-3 at pH 1.00 and more than 50 at $\mathrm{pH} 0.00$ for the same exposed area.

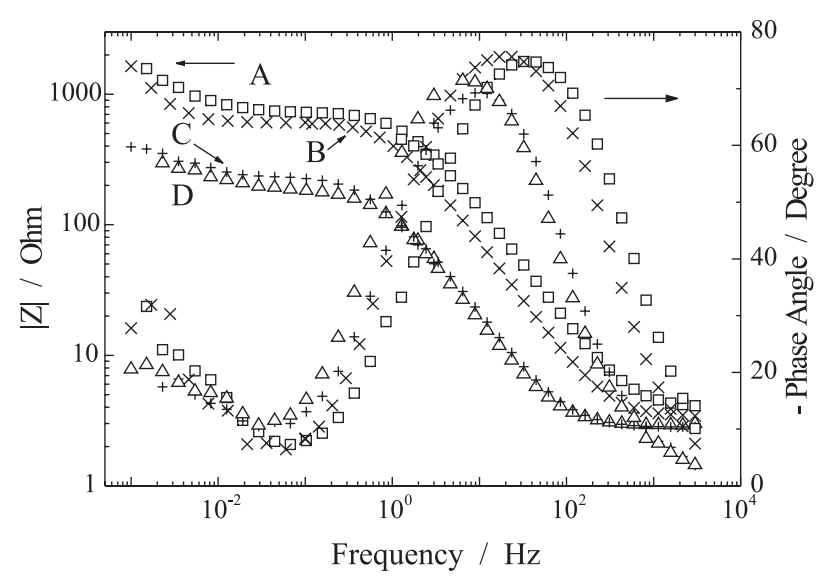

Figure 5. Electrochemical impedance of UNS S30400 steel in $1 \mathrm{~mol}$ $\mathrm{L}^{-1} \mathrm{NaCl}+1 \mathrm{~mol} \mathrm{~L}^{-1} \mathrm{HCl}$ solution at $\mathrm{pH} 1.00$ under SSRT at different stress levels: (A) $58 \mathrm{MPa}$, (B) $108 \mathrm{MPa}$, (C) $222 \mathrm{MPa}$, (D) $534 \mathrm{MPa}$.
Although in $\mathrm{pH} 1.00$ the reduction of characteristic frequency is not as clear as in $\mathrm{pH} 0.00$ electrolyte, specially bellow $0.1 \mathrm{~Hz}$, this behavior can be also attributed to parallel processes as pit occurrence, mass transport effects and mechanical perturbations that take place at the surface besides the less intense SCC. It seems that in this case these overall effects could also be the cause of the increase of the impedance modulus in this low frequency range.

\section{Current fluctuations measurements}

The PSDs of the current signal flowing through the ZRA are shown in Figure 6 for $\mathrm{pH}$ 0.00. It is important to point out that the WE was under permanent and increasing mechanical load while the CE remained unstressed. This means that the ECN measurements have been carried out on electrodes submitted to different surface conditions that acted as the driving force for the current flow between the electrodes. This experimental set-up is prone to give rise to a continuous drift of the current signal that is the probable explanation for the absence of a low-frequency plateau on the PSD as observed on Figure 6. This drift can also be a potential source of distortion of the current spectra. This statement, however, deserves an important remark. The influence of drift in electrochemical noise measurements has been extensively discussed in a previous paper co-signed by one of the present authors, ${ }^{17}$ where it was shown that drift can effectively alter the PSD level leading to the misinterpretation of results. Nevertheless, the use of highpass (HP) filtering procedures, which was one of the solutions proposed there has been avoided in the present study since under very slow strain rate conditions, the cut-off frequencies that could have been employed to eliminate the drift would be forcibly larger than the frequency components intrinsically related to the $3 \times 10^{-6} \mathrm{~s}^{-1}$ strain rate test. In other

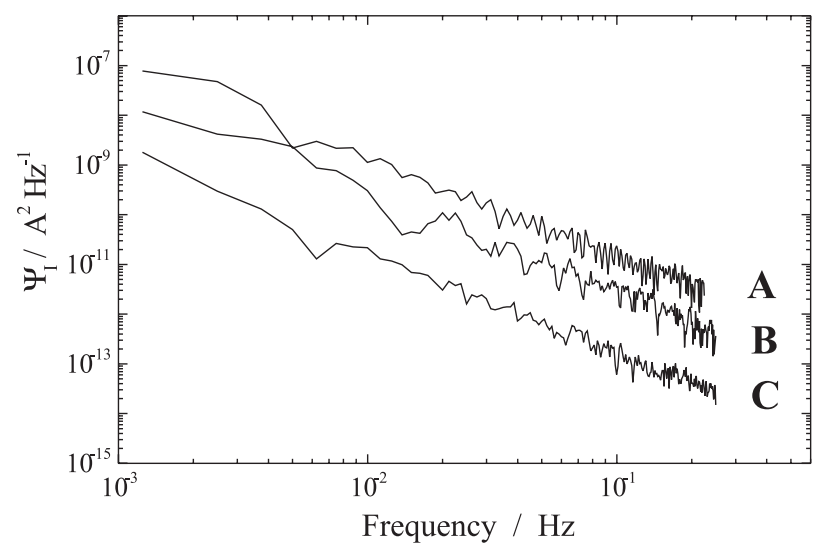

Figure 6. PSDs of the fluctuations of the current flowing through the ZRA for UNS S30400 steel in $1 \mathrm{~mol} \mathrm{~L}^{-1} \mathrm{NaCl}+1 \mathrm{~mol} \mathrm{~L}^{-1} \mathrm{HCl}$ solution at pH 0.00 at different stress levels: (A) $52 \mathrm{MPa}$, (B) 108 MPa, (C) $389 \mathrm{MPa}$. 
words, the HP filtering operation would have simply withdrawn the response of the interface to the SSRT. Furthermore, it has been shown that the Hanning window, which was employed in the measurements carried out in the present study, is a very efficient tool to strongly attenuate the distortion of the PSDs caused by drift. ${ }^{17}$ In this sense, the lack of low-frequency plateaus in Figure 6 must not be ascribed to the presence of drift in the measured signal, but to the existence of some very slow electrochemical processes that would not be conveniently resolved in the frequency range investigated ( $\mathrm{f}>1 \times 10^{-3} \mathrm{~Hz}$ ). This was already true in the analysis of potential fluctuations obtained for the same material in the presence of chloride even in the absence of mechanical stress. ${ }^{7}$ From what has been discussed above and from the fact that the analogical/digital conversion has been conveniently performed after anti-aliasing low-pass filtering, the PSDs presented in the present study are not to be ascribed to any kind of artefact whatsoever (for a more complete discussion about artefacts in electrochemical noise measurements see references 16, 17 and 24).

The amplitude of the PSDs in Figure 6 decreases monotonically following the continuous evolution of surface cracking and elongation. This PSD evolution is corroborated by the time records obtained during the experiments as it can be seen in Figures 7-9 for different load levels. Vertical axes are presented in $\Delta \mathrm{I}$ as the DC values have been previously eliminated to allow small amplitude fluctuations to be captured. The elimination of the DC value in these figures is justified since the mean current value in the specific experimental conditions of the present paper can not be straightforwardly related to the corrosion degree because of the continuous increase of the depassivated area which precludes the definition of the actual current density. Furthermore, without the elimination of the DC value one can not proceed to the high level amplification required to the measurement of small amplitude fluctuations like those in the inset of Figure 9. It can be seen that as the load increases the overall amplitude of the current fluctuations decreases. Furthermore, at lower stress levels (e.g. 108MPa, Figure 7), signals appeared as the result of very numerous overlapping transients that became less frequent and of lower amplitudes as the test went on. In fact, at the intermediate stages of the SSRT only some largely spaced transients, as the one present in Figure 8 for 540MPa were present. They show a steep rise followed by a slow exponential-like decay, which can be related to surface cracks or film breakdowns. At the final stages of the SSRT the sample was submitted to mechanical instabilities and fast crack propagation so that the signal presents a marked drift (Figure 9) that once eliminated allows very small fluctuations to be revealed (Figure 9, inset).

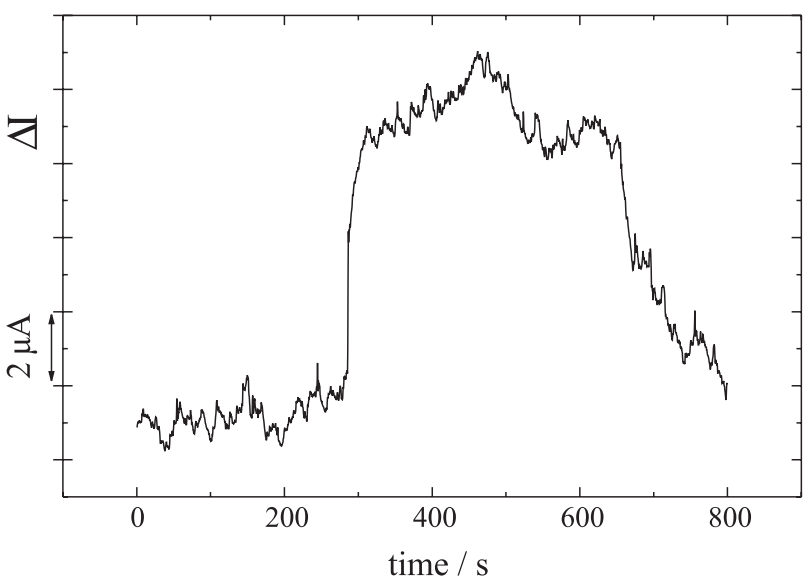

Figure 7. Time record of the current fluctuations flowing through the ZRA for UNS S30400 steel in $1 \mathrm{~mol} \mathrm{~L}^{-1} \mathrm{NaCl}+1 \mathrm{~mol} \mathrm{~L}^{-1} \mathrm{HCl}$ solution at $\mathrm{pH} 0.00$. Stress level of $108 \mathrm{MPa}$ corresponding to the PSD of Figure 6B.

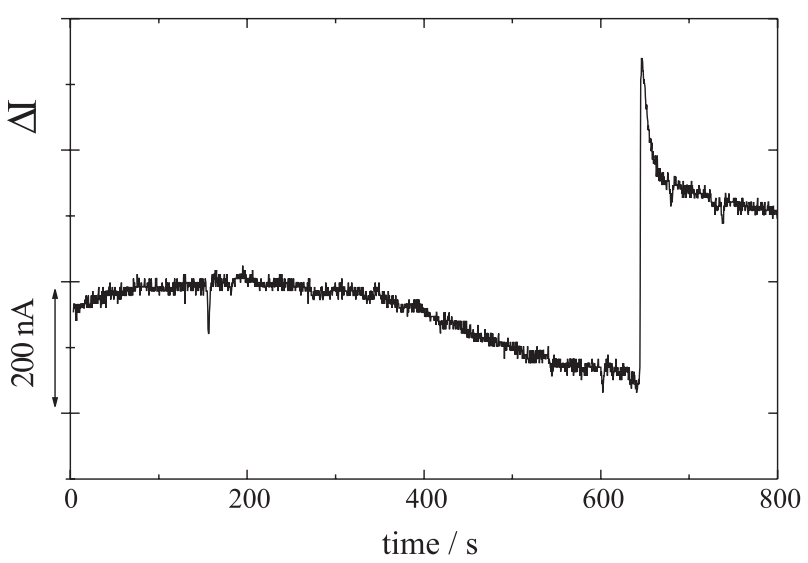

Figure 8. Time record of the current fluctuations flowing through the ZRA for UNS S30400 steel in $1 \mathrm{~mol} \mathrm{~L}^{-1} \mathrm{NaCl}+1 \mathrm{~mol} \mathrm{~L}^{-1} \mathrm{HCl}$ solution at $\mathrm{pH}$ 0.00. Stress level of $540 \mathrm{MPa}$.

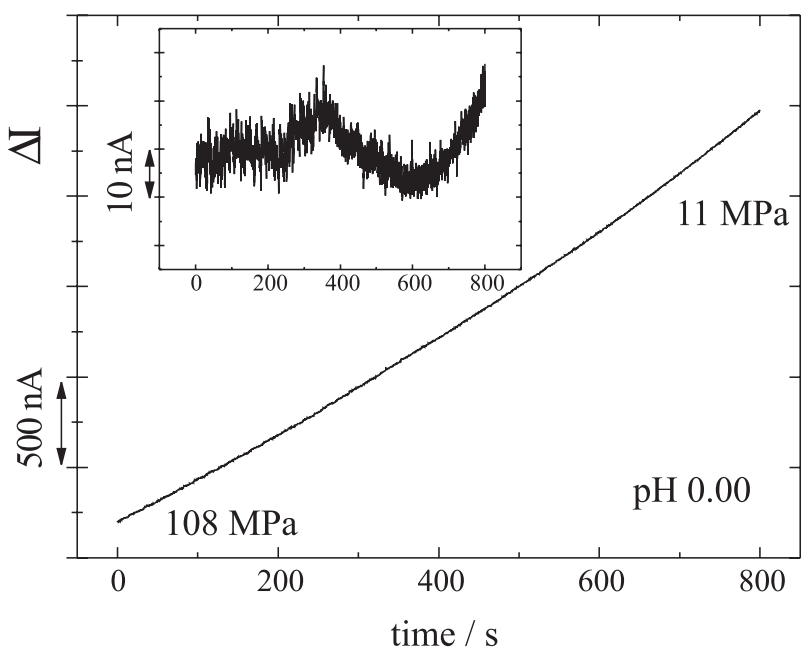

Figure 9. Time record of the current fluctuations flowing through the ZRA for UNS S30400 steel in $1 \mathrm{~mol} \mathrm{~L}^{-1} \mathrm{NaCl}+1 \mathrm{~mol} \mathrm{~L}^{-1} \mathrm{HCl}$ solution at $\mathrm{pH} 0.00$ at the end of SSRT at $\mathrm{pH} 0.00$. Inset: current fluctuations obtained after drift elimination. 
These results seem to be in good agreement with those related by Leban et al., ${ }^{25}$ who ascribed most of the electrochemical noise associated to SCC to uniform corrosion processes taking place at the interface in spite of the presence of localized phenomena leading to cracking. The general picture can be summarized as follows: at the first stages of the SSRT the sample is not submitted to an extensive generalized attack, but the onset of cracking entails the occurrence of several current transients (Figures $6 \mathrm{~A}$ and 7). As mentioned before, the elongation progress entails some metallurgical transformation of the baseaustenite into martensite type $\alpha$ '. The presence of this new active phase favours the occurrence of uniform dissolution of the strained sample surface, which is known to give PSDs of lower amplitudes than those generated by localized corrosion. ${ }^{26}$ Hence, the reduction in PSD amplitudes and the change in the time record profiles during SSRT (Figures 6B and C, 8 and 9) can be at least partially attributed to the spreading out of uniform corrosion over the metallic surface assisted by the steadily generation of martensite, besides the fact that the high mechanical stress, itself, makes the metallic surface more active. Differently to what has been discussed from the polarization curves, it can be seen that ECN measurements were able to detect changes in the corrosive attack profile with increasing mechanical loading.

A complementary interpretation of the amplitude decrease of the PSDs in Figure 6 is related to the relative impedance ratio between the $\mathrm{WE}$ and the $\mathrm{CE}$. As it has been pointed out by Gomez-Duran and Macdonald, ${ }^{15}$ when cracking occurs, part of the overall current flow can be distributed on the WE surface itself, instead of splitting the current between the WE (anodic part) and the CE (cathodic counterpart). The ZRA detects only the fraction of external current that flows via the external cylinder (CE). Hence, depending on the values of the impedances of the WE and the $\mathrm{CE}$, a parcel of the ECN can actually bypass the ZRA through the local interfacial electrochemical impedance, as confirmed by the model developed by Bertocci et al. ${ }^{27}$ Consequently, if the ratio between the relative impedances changes during the test, the current flow passing by the ZRA is also modified. This seems to be the case in the present study. In fact, the CE surface is about 19 times that of the WE, so that at the first stages one should expect it to have lower impedance values than the WE. In these conditions, most of the current flow would be effectively picked-up by the ZRA. Nevertheless, as shown in Figure 4, there is an approximately 25 -fold decrease of the WE impedance modulus in the low frequency range during the SSRT for $\mathrm{pH}$ 0.00 , whilst the impedance of the $\mathrm{CE}$, which is not mechanically loaded, is not expected to decrease. This means that the part of the current fluctuations looping back to the WE would become higher as the SSRT goes on so that less current would be detected by the ZRA and the PSD would have lower amplitudes as in Figure 6.

Figure 10 shows the PSDs of current fluctuations obtained at $\mathrm{pH}$ 1.00. In this less acidic medium the uniform dissolution is significantly reduced as it was already shown by means of polarization curves (see Figure 3). The surface film is more stable and the impedance values are considerably larger than at pH 0.00 ( $c f$. Figures 4 and 5). These higher impedance values and also the fact that the decrease of the modulus is limited to a 5-fold reduction (instead of 25 at $\mathrm{pH} 0.00$ ), indicate that the current loop-back effect discussed above must be of minor importance at these experimental conditions. Furthermore, at the first stages of the SSRT (Figure 10 curve A) the sample shows negligible corrosion and very little mechanical damage. As the SSRT goes on, the surface film is locally broken down by mechanical stress and some pits, yielding higher current fluctuations. Therefore, the PSDs, inversely to what occurred at $\mathrm{pH} 0.00$, present a general trend of increasing amplitudes. These results indicate that the comparison between PSDs obtained at different $\mathrm{pH}$ values is not straightforward, since they represent different interfacial conditions that lead to differences in the behaviour of the ECN. It is worth noticing that this interpretation would probably not be achieved with the help of only one of the techniques used in this study. In fact, neither the impedance diagrams nor the PSDs of the electrochemical noise, if treated separately, would have shown clear evidences of this change in the type of corrosive attack.

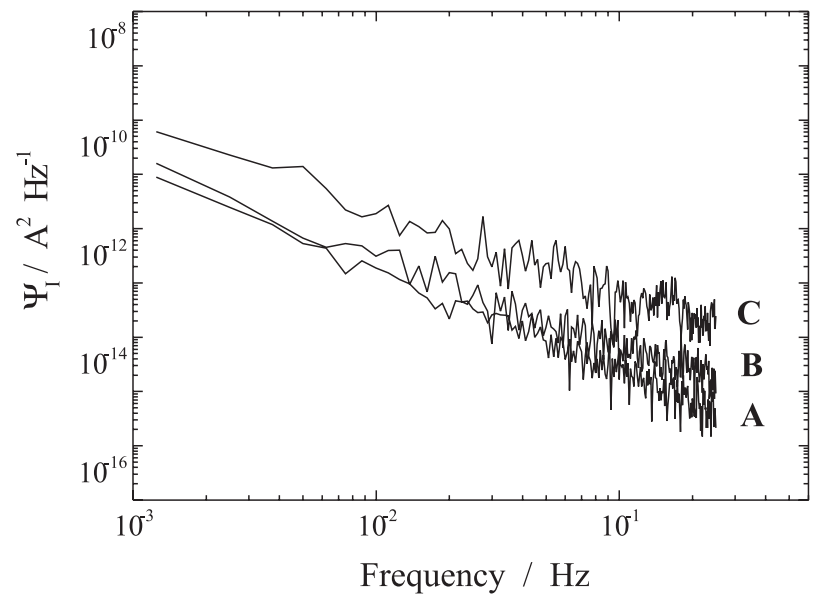

Figure 10. PSDs of the fluctuations of the current flowing through the ZRA for UNS S30400 steel in $1 \mathrm{~mol} \mathrm{~L}^{-1} \mathrm{NaCl}+1 \mathrm{~mol} \mathrm{~L}^{-1} \mathrm{HCl}$ solution at $\mathrm{pH} 1.00$ at different stress levels: (A) $41 \mathrm{MPa}$, (B) 119 $\mathrm{MPa}$, (C) $403 \mathrm{MPa}$.

\section{Conclusions}

The combined use of EIS and ECN techniques allowed the differentiation between some aspects of the stress 
corrosion cracking of austenitic stainless steel taking place at very acidic environments $(\mathrm{pH} 0.00$ and 1.00) in the presence of chloride ions at room temperature. The results obtained in the present study indicated that at $\mathrm{pH} 0.00$ the surface deterioration is mainly uniform while localized attack seems to govern the dissolution process at $\mathrm{pH} 1.00$, which is in good agreement with results obtained from polarization curves and weight loss measurements.

Electrochemical noise measurements both in the time and frequency domains were shown to provide information about the dynamic evolution of the corrosive attack during slow strain rate tests that were not accessible by stationary techniques like polarization curves.

\section{References}

1. Newman, R. C., Procter, R. P. M.; Br. Corros. J. 1990, 25, 259.

2. Hänninen, E.; Internat. Metals Review 1979, 3, Review 241, 85.

3. Torchio, S.; Corros. Sci. 1980, 20, 555.

4. Juang, H. K.; C. Altstetter, C.; Corrosion 1990, 46, 881.

5. Carranza, R. M.; Galvele, J. R.; Corros. Sci. 1988, 28, 233.

6. Staehle, R. W.; Stress Corrosion Cracking: Theory of Stress Corrosion Cracking in Alloys, NATO: Brussel, 1971.

7. Bastos, I. N.; Gomes, J. A C. P.; Nogueira, R. P.; Huet, H.; J. Braz. Chem. Soc. 1995, 6, 59.

8. Oltra, R.; Gabrielli, C.; Huet, F.; Keddam, M.; Electrochim. Acta 1986, 31, 501.

9. Zhi, F.; Yinshum, W.; Bei, C.; Rizhang, Z.; Abstracts of the Progress in the Understanding and Prevention of Corrosion, Barcelona, Spain, 1993.

10 Galvele, J. R.; de Wexler, S. B.; Gardiazabal, I.; Corrosion 1975, 10, 31 .

11. Zucchi, F.; Trabanelli, G.; Frignani, A.; Zucchini. M. ; Corros. Sci. 1978, 18, 87.

12. Bianchi, G.; Mazza, F.; Torchio, S.; Corros. Sci. 1973, 13, 165 .
13. Nishimura, R.; Maeda, Y.; Corros. Sci. 2004, 46, 755.

14. Wells, D. B.; Stewart, J.; Davidson, R.; Scott, P. M.; Williams, D. E.; Corros. Sci. 1992, 43, 39.

15. Gomez-Duran, M.; Macdonald, D. D.; Corros. Sci. 2003, 45, 1455.

16. Bastos, I. N.; Nogueira, R. P; Rosseau, P.; Huet, F.; J. Electrochem. Soc. 2000, 147, 671.

17. Bertocci, U.; Huet, F.; Nogueira, R. P.; Rousseau, P. ; Corrosion 2002, 58, 337.

18. ASTM G31-72; Standard Practice for Laboratory Immersion Corrosion Testing of Metals, ASTM International: West Conshohocken, USA, 1999.

19. Huet, F.; Nogueira, R.P.; Normand, B.; Takenouti, H.; ASM Handbook, Corrosion: Fundamentals, Testing and Protection, Materials Park: USA, 2003, p. 52, vol. 13A.

20. Bastos, I. N.; Gomes, J. A. C. P.; Tavares, S. S. M.; Braz. J. Mater. Sci. Eng. 2001, 4, 15.

21. Chen, H.; Guo, X. Z.; Chu, W. Y.; Gao, K. W.; Wang, Y. B.; Su, Y. J.; Qiao, L.; J. Mater. Sci. Eng. 2003, A358, 122

22. Bosch, R. M.; Moons, F.; Zheng, J. H.; Corrosion 2001, 57, 532.

23. Touzet, M.; Puiggale, M.; Cid, M.; Desjardins, D.; Corros. Sci. 1994, 36, 815.

24. Bertocci, U.; Huet, F.; Nogueira, R. P.; Corrosion 2003, 59, 629

25. Leban, M.; Dollek, V.; Legat, A.; Kuhar, V.; Abstract of the European Congress of Corrosion, Utrecht, Holland, 1998.

26. Huet, F. In The Electrochemical Noise Technique, Methods for Corrosion Science and Engineering; Marcus, P.; Mansfeld, F., eds.; Marcel Dekker Inc.: New York, 2004, in press.

27. Bertocci, U.; Gabrielli, C.; Huet, F.; Keddam, M.; Rosseau, P.; J. Electrochem. Soc. 1997, 144, 31.

Received: November 8, 2004 Published on the web: March 9, 2005 